KHAZANAH MULTIDISIPLIN

VOL 1 NO 22020

https://journal.uinsgd.ac.id/index.php/kl

\title{
DEKOMPOSISI MODUL AUTOMORFISMA INVARIAN ATAS MODUL KUASI-INJEKTIF DAN MODUL SQUARE-FREE
}

\author{
Inne Syafrian Putri \\ Matematika, FST UIN Sunan Gunung Djati Bandung, Indonesia \\ Email: innesyafrian@uinsgd.ac.id
}

Diterima : 1 Oktober 2020, Revisi : 11 Oktober 2020 Disetujui : 29 Oktober 2020

\begin{abstract}
Let $M$ be a module over ring $R$. An injective hull of $M$, denoted by $E(M)$, is an injective module which contains $M$ as its essential submodule. If $\mathrm{M}$ is invariant under any automorphism of $\mathrm{E}(\mathrm{M})$, then $\mathrm{M}$ is called an automorphism invariant module. An isomorphism between two essential submodule of automorphism invariant module $\mathrm{M}$ can be extended into endomorphism or automorphism of $M$. Direct summand of an automorphism module is automorphism invariant. In this article showed that an automorphism invariant module is decomposable as quasi-injective module and squarefree module which is mutually orthogonal and relatively injective.

Keywords: automorphism invariant module, essential submodule, quasi-injective module, square-free module
\end{abstract}

\begin{abstract}
ABSTRAK
Misalkan $M$ adalah modul atas ring $R$. Injektif hull dari $M$, dinotasikan $E(M)$, adalah suatu modul injektif yang memuat $M$ sebagai submodul essensialnya. Jika $M$ invarian dibawah sebarang automorfisma dari $E(M)$ maka $M$ disebut modul automorfisma invarian. Isomorfisma diantara dua submodul essensial dari modul automorfisma invaria $\mathrm{n} M$ dapat diperluas menjadi endomorfisma atau automorfisma dari $M$. Komponen langsung dari modul automorfisma invarian juga merupakan modul automorfisma invarian. Dalam tulisan ini dibuktikan bahwa modul automorfisma invarian dapat didekomposisi atas modul kuasi-injektif dan modul square-free yang saling ortogonal dan relatifinjektif.

Kata Kunci: modul automorfisma invarian, submodul essensial, modul kuasi-injektif, modul square-free
\end{abstract}

\section{PENDAHULUAN}

Dalam aljabar linier telah diperkenalkan tentang ruang vektor atas suatu lapangan. Kemudian dalam struktur aljabar, konsep ruang vektor ini digeneralisasi menjadi modul atas ring (Sri Wahyuni dkk, 2016). Berbagai jenis modul atas ring juga disajikan dalam teori modul seperti modul bebas, modul faktor, modul siklik, modul torsi, modul proyektif dan sebagainya (Keating, 1998).

Modul atas suatu ring yang telah diteliti berkembang dengan berbagai nama sesuai sifat-sifat modul dan ring yang digunakan. Salah 
satunya adalah modul atas suatu ring yang invarian di bawah sebarang automorfisma dari injektif hull-nya. Modul ini oleh Lee dan Zhoe disebut modul automorfisma invarian. Dengan kata lain, sebarang modul $M$ atas ring $R$ disebut automorfisma invarian jika $\sigma(M) \subseteq M$ untuk setiap automorfisma $\sigma$ dari $E(M)$, dengan $E(M)$ adalah injektif hull dari $M$ (Singh dan Srivastava, 2012).

Suatu modul ada yang dapat dinyatakan sebagai jumlah langsung dua atau lebih submodulnya (decomposable module) dan ada juga yang tidak (indecomposable module). Modul yang tidak dapat didekomposisi contohnya adalah modul sederhana, yaitu modul tak nol yang tidak mempunyai submodul sejati (Keating, 1998).

Pada penelitian ini ditunjukkan bahwa modul automorfisma invarian dapat didekomposisi atas modul kuasi-injektif dan modul squarefree. Selain itu, pembahasan tentang submodul essensial, injektif hull dan beberapa lema diberikan untuk mendukung pembuktian dekomposisi modul automorfisma invarian. Masalah penelitian juga dibatasi yaitu semua ring yang digunakan adalah ring dengan unsur satuan.

\section{METODE PENELITIAN}

Metode penelitian ini adalah kualitatif dengan menganalisis suatu masalah melalui studi literatur. Kajian dan teorema yang dibahas adalah hasil kajian pustaka dan bukan merupakan hasil baru. Namun begitu, cara penulisan, sudut pandang dan pembuktian yang diberikan dalam penelitian ini dipaparkan dalam gaya berbeda dengan rujukan, yaitu lebih detail dan jelas sehingga mudah dipahami.

\section{HASIL DAN PEMBAHASAN}

Submodul dari suatu modul atas ring $R$ adalah juga suatu modul atas $R$. Submodul yang hanya terdiri atas satu anggota, yaitu unsur nol disebut modul nol. Setiap submodul dari suatu modul atas $R$ selalu memuat unsur 
KHAZANAH MULTIDISIPLIN

VOL 1 NO 22020

https://journal.uinsgd.ac.id/index.php/kl

nol sebagai identitas terhadap penjumlahan. Oleh karena itu, setiap dua submodul dari suatu modul selalu mempunyai irisan.

\section{Submodul Essensial}

Suatu submodul yang irisannya tak nol dengan setiap submodul lainnya disebut submodul essensial. Misalkan $M$ adalah modul atas $R$ dan $N \leq M$ adalah submodul dari $M$. Submodul $N$ disebut submodul essensial dari $M$, ditulis $N$ ess $_{R} M$ atau $N$ ess $M$, jika dan hanya jika $X \cap$ $N \neq 0$ untuk setiapsubmodultak nol $X \leq M$.

Berdasarkan definisi di atas, suatu submodul $N \leq M$ disebut essensial di $M$ jika $N$ memiliki irisan tak nol dengan setiapsubmodul tak nol dari $M$. Dalam hal ini M disebut juga essential extension dari $N$. Definisi ini ekivalen dengan mengatakan bahwa $N$ disebut essensial di $M$ jika untuk sebarang submodul $L \leq M$,

$$
L \cap N=0 \Rightarrow L=0 .
$$

Submodul essensial bersifat transitif, artinya jika L ess $N$ dan $N$ ess $M$ maka $L$ ess $M$. Sebagai bukti, misalkan $X$ submodul tak nol dari $M$. Karena $N$ ess $M$ maka $X \cap N \neq 0$. Tetapi L ess $N$ berakibat $(X \cap N) \cap$ $L \neq 0$. Diperoleh $X \cap L \neq 0$.

Sebagai contoh submodul essesensial, $M$ ess $M$ untuk sebarang $M$ modul atas $R$ dan $n \mathbb{Z}$ ess $\mathbb{Z}$ untuk sebarang $n \in \mathbb{Z}$.

Dalam teori modul telah diperkenalkan bahwa jumlah dari sebarang dua submodul dari suatu modul adalah suatu submodul juga (Keating, 1998). Akan tetapi jumlah sebarang dua submodul belum tentu bersifat essensial di modul tersebut.

Berikut diberikan definisi komplemen suatu submodul yang akan menjadi syarat perlu agar jumlah dua submodul bersifat essensial di modulnya.

Misalkan $A$ dan $B$ adalah submodul dari $M$. Submodul $B$ disebut komplemen dari $A$ di $M$ jika $B$ maksimal diantara semua submodul dari $M$ yang irisannya dengan $A$ adalah trivial. Dengan kata lain $B=$ 
$\operatorname{Maks}\left\{M_{i} \mid M_{i} \cap A=0, M_{i} \leq M\right\}$.

Contoh 1. Misalkan $M=\mathbb{Z}_{12}$ modul atas $\mathbb{Z}$ dan $C=\{\overline{0}, \overline{4}, \overline{8}\}$ submodul dari $\mathbb{Z}_{12}$. Akan dicari komplemen dari $C$ di $\mathbb{Z}_{12}$. Perhatikan bahwa $A=\{\overline{0}\}, B=\{\overline{0}, \overline{6}\}, C=\{\overline{0}, \overline{4}, \overline{8}\}, D=\{\overline{0}, \overline{3}, \overline{6}, \overline{9}\}$, dan $E=\{\overline{0}, \overline{2}, \overline{4}, \overline{6}, \overline{8}, \overline{10}\}$ adalah submodul-submodul sejati dari $\mathbb{Z}_{12}$. Submodulyang irisannya trivial dengan $C$ adalah $A, B$ dan $D$. Pilih maks $\{A, B, D\}=D$. Diperoleh $D$ komplemen dari $C$.

Jumlah suatu submodul dari $M$ dengan komplemennya di $M$ bersifat essensial di $M$. Hal ini dibuktikan pada teorema berikut.

Teorema 2. (Anderson dan Fuller, 1974) Jika $B$ adalah komplemen dari $A$ di $M$ maka $A \oplus B$ ess $M$.

Bukti : Jelas $A \oplus B$ submodul dari $M$. Misalkan $L$ sebarang submodul tak nol dari M. Akan ditunjukkan $(A \oplus B) \cap L \neq 0$. Jika $L \cap$ $A \neq 0$ maka $(A \oplus B) \cap L \neq 0$. Jika $L \cap A=0$ maka $L$ termuat di komplemen dari $A$ yaitu $B$ sehingga diperoleh $(A \oplus B) \cap L \neq 0$. Terbukti $(A \oplus B)$ ess $M$.

\section{Modul Injektif}

Submodul essensial memiliki kaitan dengan modul injektif. Jika modul $M$ merupakan submodul essensial dari suatu modul injektif maka akan muncul konsep baru yang disebut injektif hull dari $M$. Oleh karena itu perlu dikaji terlebih dahulu tentang modul injektif.

Definisi 3. Misalkan $M$ adalah modul atas $R$.

(i) $M$ disebut modul $N$-injektif jika untuk setiap $\operatorname{submodul} N_{1} \leq$ $N$, semua homomorfisma $N_{1} \rightarrow M$ bisa diperluas menjadi homomorfisma $N \rightarrow M$.

(ii) $M$ disebut modul injektif jika $M$ adalah $N$-injektif untuk setiap $N$ modul atas $R$.

Contoh sederhana dari modul injektif adalah modul reguler $\mathrm{F}$ atas $\mathrm{F}$, dengan F sebarang lapangan. 
KHAZANAH MULTIDISIPLIN

VOL 1 NO 22020

https://journal.uinsgd.ac.id/index.php/kl

Definisi 4. Misalkan $M$ adalah modul atas $R$. Injektif hull dari $M$ adalah modul injektif $E$ yang ditentukan secara tunggal dengan $M$ ess $E$, dan ditulis $E=E(M)$.

Sebarang modul atas $R$ memiliki kaitan yang erat dengan submodul essensialnya, yaitu keduanya memiliki injektif hull yang sama. Injektif hull dari suatu modul juga berkaitan dengan injektif hull komponen langsung dari submodul essensial.

Lema 5. (Passman, 1991) Misalkan L submodul essensial dari M, maka

(i) $\quad E(L)=E(M)$,

(ii) Jika $L=L_{1} \oplus L_{2} \oplus \ldots \oplus L_{2} \operatorname{maka} E(M)=E\left(L_{1}\right) \oplus E\left(L_{2}\right) \oplus$ $\ldots \oplus E\left(L_{2}\right)$.

Bukti:

(i) Karena $L$ ess $M$ dan $M$ ess $E(M)$ maka dari sifat transitif submodul essensial diperoleh $L$ ess $E(M)$. Jadi $E(L)=E(M)$

(ii) Karena $L_{i}$ ess $E\left(L_{i}\right)$ maka $L=L_{1} \oplus L_{2} \oplus \ldots \oplus L_{2}$ ess $E=E\left(L_{1}\right) \oplus$ $E\left(L_{2}\right) \oplus \ldots \oplus E\left(L_{2}\right)$. Karena $\mathrm{E}$ adalah jumlah langsung dari modul injektif maka $\mathrm{E}$ injektif, sehingga disimpulkan $\mathrm{E}=\mathrm{E}(\mathrm{L})$. Dari (i) diperoleh $\mathrm{E}=\mathrm{E}(\mathrm{L})=\mathrm{E}(\mathrm{M})$.

\section{Modul Automorfisma Invarian}

Pendefinisian modul automorfisma invarian dikarenakan modul tersebut bersifat invarian dibawah sebarang automorfisma dari injektif hull-nya. Adapun sifat-sifat modul automorfisma invarian yang akan dibahas adalah ekivalensi dari modul automorfisma invarian dan komponen-komponen langsung dari dari modul automorfisma invarian yang juga automorfisma invarian dan relatif injektif.

Definisi 6. Misalkan $M$ adalah modul atas $R$. Modul $M$ disebut 


\section{KHAZANAH MULTIDISIPLIN}

VOL 1 NO 22020

https://journal.uinsgd.ac.id/index.php/kl

modul automorfisma invarian jika dan hanya jika $\sigma(M) \subseteq M$ untuk setiap automorfisma $\sigma$ dari $E(M)$, dengan $E(M)$ adalah injektif hull dari $M$.

Definisi modul automorfisma invarian dikaitkan dengan injektif hull-nya. Injektif hull dari suatu modul injektif adalah dirinya sendiri. Oleh karena itu setiap modul injektif merupakan contoh modul automorfisma invarian. Jika injektif hull dari suatu modul merupakan hasil jumlah langsung beberapa submodulnya, dengan dua diantaranya isomorfik, maka modul tersebut dapat didekomposisi menjadi jumlah langsung dari masingmasing irisan modul tersebut dengan komponen langsung dari injektifhullnya seperti dibuktikan pada lema berikut.

Lema 7. (Singh dan Srivastava, 2012) Jika $M$ adalah modul automorfisma invarian dengan injektif hull $E(M)=E_{1} \oplus E_{2} \oplus E_{2}$ dan $E_{1} \cong E_{2} \operatorname{maka} M=\left(M \cap E_{1}\right) \oplus\left(M \cap E_{2}\right) \oplus\left(M \cap E_{3}\right)$.

Bukti :

Misalkan $E=E(M)$ injektif hull dari $M, E=E_{1} \oplus E_{2} \oplus E_{2}, \sigma$ : $E_{1} \rightarrow E_{2}$ isomorfisma, dan $\pi_{i}: E \rightarrow E_{i}(i=1,2,3)$ proyeksi kanonik. Karena $E_{i} \leq E$ dan $M$ ess $E$ maka $M \cap E_{i} \neq 0$. Misalkan $\theta=\sigma^{-1}$. Perhatikan bahwa pemetaan $\lambda_{1}: E \rightarrow E$ dengan aturan $\lambda_{1}\left(x_{1}, x_{2}, x_{3}\right)=$ $\left(x_{1}, \sigma\left(x_{1}\right)+x_{2}, x_{3}\right)$ adalah suatu automorfisma dari $E$. Karena $M$ adalah modul automorfisma invarian maka $M$ invarian dibawah $\lambda_{1}$ dan $I_{E}$, dengan $I_{E}$ pemetaan identitas dari $E$.

Akibatnya

$$
\left(\lambda_{1}-I_{E}\right)(M)=\lambda 1(M)-I_{E}(M) \subseteq M .
$$

Jadi M juga invarian dibawah $\lambda_{1}-I_{E}$.

Buat pemetaan $\lambda_{2}: E \rightarrow E$ dengan aturan $\lambda_{2}\left(x_{1}, x_{2}, x_{3}\right)=\left(x_{1}+\right.$ $\left.\theta\left(x_{2}\right), x_{2}, x_{3}\right)$. Jelas $\lambda_{2}$ adalah automorfisma dari $E$. Sama dengan penjelasan sebelumnya, $M$ invarian di bawah $\lambda_{2}-I_{E}$, yaitu $\left(\lambda_{2}-I_{E}\right)(M) \subseteq$ $M$. Misalkan $x=\left(x_{1}, x_{2}, x_{3}\right) \in M$, dengan $x_{i} \in E_{i}$ maka $\left(\lambda_{1}-I_{E}\right)(x)=$ $\left(0, \sigma\left(x_{1}\right), 0\right) \in M \operatorname{dan}\left(\lambda_{2}-I_{E}\right)(x)=\left(\theta\left(x_{2}\right), 0,0\right) \in M$.

Selanjutnya 


$$
\left(\lambda_{1}-I_{E}\right)\left(\left(\theta\left(x_{2}\right), 0,0\right)\right)=\left(0, \sigma \theta\left(x_{2}\right), 0\right)=\left(0, x_{2}, 0\right)=x_{2} \in M .
$$

Diperoleh $x_{2} \in M \cap E_{2}$. Dengan cara yang sama,

$$
\left(\lambda_{2}-I_{E}\right)\left(\left(0, \sigma\left(x_{1}\right), 0\right)\right)=\left(\theta \sigma\left(x_{1}\right), 0,0\right)=\left(x_{1}, 0,0\right)=x_{1} \in M,
$$

yang berarti $x_{1} \in M \cap E_{1}$. Akibatnya $x-x_{1}-x_{2}=x_{3} \in M$, yaitu $x_{3} \in$ $M \cap E_{3}$. Jadi diperoleh $x=\left(x_{1}, x_{2}, x_{3}\right)=x_{1}+x_{2}+x_{3} \in\left(M \cap E_{1}\right) \oplus$ $\left(M \cap E_{2}\right) \oplus\left(M \cap E_{3}\right)$, yaitu $M \subseteq\left(M \cap E_{1}\right) \oplus\left(M \cap E_{2}\right) \oplus\left(M \cap E_{3}\right)$. Karena $M \cap E_{i} \subseteq M$ maka $\left(M \cap E_{1}\right) \oplus\left(M \cap E_{2}\right) \oplus\left(M \cap E_{3}\right) \subseteq M$. Terbukti $M=\left(M \cap E_{1}\right) \oplus\left(M \cap E_{2}\right) \oplus\left(M \cap E_{3}\right)$.

Untuk melihat suatu modul adalah automorfisma invarian atau bukan, tidak harus melalui injektif hull-nya. Teorema berikut memberikan ekivalensi modul automorfisma invarian dengan perluasan isomorfisma antara dua submodul essensialnya menjadi endomorfisma atau automorfisma dari modul tersebut.

Teorema 8. (Lee dan Zhoe, 2013) Misalkan M adalah modul kanan atas $R$ maka pernyataan berikut ekivalen:

(i) Madalah modul automorfisma-invarian

(ii) Setiap isomorfisma diantara dua submodul essensial dari $M$ bisa diperluas menjadi automorfisma dari $M$

(iii) Setiap isomorfisma diantara dua submodul essensial dari $M$ bisa diperluas menjadi endomorfisma dari $M$

Bukti:

(i) $\Rightarrow$ (ii) Misalkan $X$ dan $Y$ submodul essensial dari $M \operatorname{dan} \alpha: X \rightarrow Y$ suatu isomorfisma, maka terdapat endomorfisma $\beta: E(M) \rightarrow E(M)$ sehingga $\left.\beta\right|_{X}=\alpha$. Lebih lanjut $\beta$ adalah automorfisma dari $E(M)$. Karena $M$ automorfisma invarian maka $\beta(M) \subseteq M$ dan $\beta^{-1}(M) \subseteq M$, sehingga $\left.\beta\right|_{M}$ adalah automorfisma dari $M$ yang merupakan perluasan dari $\alpha$.

(ii) $\Rightarrow$ (iii) Jelas

(iii) $\Rightarrow$ (i) Misalkan $\sigma$ adalah automorfisma dari $E(M), Y=\sigma(M) \cap M$, $X=\sigma^{-1}(Y)$ dan $\alpha=\left.\sigma\right|_{X}$. Karena $\sigma$ bijeksi maka $X=\{x \in M \mid \sigma(x) \in Y\}$. 
Lebih lanjut $X$ dan $Y$ adalah submodul essensial dari $M \operatorname{dan} \alpha: X \rightarrow Y$ suatu isomorfisma. Berdasarkan (iii), $\alpha$ diperluas menjadi endomorfisma $\beta$ dari M. Misalkan $y \in Y \cap(\sigma-\beta)(M)$ dan tulis $y=(\sigma-\beta)(x)=\sigma(x)-$ $\beta(x)=\alpha(x)-\beta(x)=0$. Diperoleh $Y \cap(\sigma-\beta)(M)=0$. Karena $Y$ ess $E(M)$ diperoleh $(\sigma-\beta)(M)=0$ sehingga $\sigma(M)=\beta(M) \subseteq M$.

Sifat modul automorfisma invarian selanjutnya yang akan dibahas adalah terkait dengan komponen langsungnya. Jika suatu modul automorfisma invarian merupakan jumlah langsung dari dua atau lebih modul, maka setiapkomponen langsungnya juga automorfisma invarian.

Lema 9. (Lee dan Zhoe, 2013) Komponen langsung dari modul automorfisma invarian adalah automorfisma invarian.

Bukti:

Misalkan $N$ komponen langsung dari $M$, tulis $M=N \oplus P$. Misalkan $X$ ess $N, Y$ ess $N$ dan $\quad \alpha: X \rightarrow Y$ suatu isomorfisma. Diperoleh $(X \oplus P)$ ess $M,(Y \oplus P)$ ess $M$ dan $\alpha+i_{P}: X \oplus P \rightarrow Y \oplus P$ isomorfisma. Karena $M$ modul automorfisma invarian, $\alpha+i_{P}$ dapat diperluas menjadi endomorfisma $\beta$ dari $M$ berdasarkan Teorema 8 . Misalkan $i: N \rightarrow M$ inklusi dan $\pi: M \rightarrow N$ proyeksi sepanjang $P$, maka $\pi \beta i$ adalah endomorfisma dari $N$ yang jelas merupakan perluasan dari $\alpha$. Berdasarkan Teorema 8 terbukti $N$ adalah modul automorfisma-invarian.

Selain merupakan modul automorfisma-invarian, komponen langsung dari modul automorfisma invarian bersifat relatifinjektif. Dengan kata lain, jika $A$ dan $B$ adalah komponen langsung dari modul automorfisma invarian, maka $A$ adalah $B$-injektif dan $B$ adalah $A$-injektif.

Teorema 10 (Lee dan Zhoe, 2013) Jika jumlah langsung $M_{1} \oplus M_{2}$ adalah automorfisma invarian maka $M_{1}$ dan $M_{2}$ relatifinjektif.

Bukti: 
KHAZANAH MULTIDISIPLIN

VOL 1 NO 22020

https://journal.uinsgd.ac.id/index.php/kl

Asumsikan $f: A \rightarrow M_{1}$ homomorfisma dengan $A \leq M_{2}$. Akan ditunjukkan $f$ dapat diperluas menjadi homomorfisma dari $M_{2}$ ke $M_{1}$. Misalkan $B$ adalah komplemen dari $A$ di $M_{2}$. Diperoleh $(A \oplus B)$ ess $M_{2}$ dan $f$ diperluas menjadi homomorfisma $g: A \oplus B \rightarrow M_{1}$ dengan $g(B)=0$. Misalkan $\quad C:=A \oplus B$, definisikan $\alpha: M_{1} \oplus C \rightarrow M_{1} \oplus M_{2}$ dengan $\alpha(x, c)=(x+g(c), c)$ untuk sebarang $x \in M_{1} \operatorname{dan} c \in C$. Jelas $\alpha$ suatu monomorfisma. Lebih lanjut $\alpha\left(M_{1} \oplus C\right)=M_{1} \oplus C$ adalah submodul essensial di $M_{1} \oplus M_{2}$. Karena $M_{1} \oplus M_{2}$ automorfisma invarian, $\alpha$ dapat diperluas menjadi endomorfisma $\beta$ dari $M_{1} \oplus M_{2}$. Misalkan $i: M_{2} \rightarrow M_{1} \oplus$ $M_{2}$ injeksi kanonik dan $\pi: M_{1} \oplus M_{2} \rightarrow M_{1}$ proyeksi kanonik, maka $\pi \beta i$ : $M_{2} \rightarrow M_{1}$ adalah perluasan dari $f$. Terbukti $M_{1}$ adalah $M_{2}$-injektif.

\section{Dekomposisi Modul Automorfisma Invarian}

Sebelum membahas teorema utama tentang dekomposisi modul automorfisma invarian, perlu dipahami beberapa definisi berikut ini.

Definisi 11. Misalkan $M$ modul atas $R$.

(i) Modul $M$ disebut kuasi-injektifjika $M$ adalah $M$-injektif

(ii) Modul $M$ disebut square-free jika $M$ tidak memuat jumlah langsung dari dua submodul yang isomorfik.

(iii) Dua modul disebut saling ortogonal jika keduanya tidak memuat submodul tak nol yang isomorfik.

(iv) Closed submodule dari modul $M$ adalah submodul dari $M$ yang tidak mempunyai essential extension sejati di $M$.

(v) Essential closure dari submodul $A \leq M$ adalah suatu closed submodul yang memuat $A$ sebagai submodul essensialnya.

Syarat modul kuasi-injektif lebih lemah dari pada modul injektif. Dengan kata lain, modul $M$ disebut kuasi-injektif jika untuk setiap submodul $N \leq M$, semua homomorfisma dari $N$ ke $M$ bisa diperluas menjadi endomorfisma dari $M$. Hal ini mengakibatkan setiapmodul injektif 
KHAZANAH MULTIDISIPLIN

VOL 1 NO 22020

https://journal.uinsgd.ac.id/index.php/kl

adalah modul kuasi-injektif. Berikut ini adalah teorema tentang dekomposisi modul automorfisma invarian atas modul kuasi-injektif dan modul square-free beserta sifat saling ortogonal dan relatif injektif diantara keduanya.

Teorema 12. (Noyan dkk, 2013) Misalkan $M$ modul automorfisma invarian maka $M=X \oplus Y$ dengan $X$ modul kuasi-injektif dan $Y$ modul square-free yang ortogonal terhadap $X$. Dalam hal ini $X$ dan $Y$ relatifinjektif.

Bukti :

Misalkan $M$ modul automorfisma invarian dan $\Gamma=$ $\{(A, B, f) \mid A, B \leq M, A \cap B=0, f: A \rightarrow B$ isomorfisma $\}$ himpunan terurut dengan urutan $(A, B, f) \leq\left(A^{\prime}, B^{\prime}, f^{\prime}\right)$ jika $A \subseteq A^{\prime}, B \subseteq B^{\prime}$ dan $f^{\prime}$ perluasan dari $f$. Perhatikan bahwa $\Gamma$ terurut parsial dan setiap rantai di $\Gamma$ mempunyai batas atas, berdasarkan Lema Zorn, $\Gamma$ mempunyai elemen maksimal. Misalkan $(A, B, f)$ elemen maksimal di $\Gamma$ dan $C^{\prime}$ komplemen dari $A \oplus B$ di $M$. Akan ditunjukkan $C^{\prime}$ square-free.

Andaikan $C^{\prime}$ tidak square-free maka terdapat submodul tak nol $C_{1}$ dan $C_{2}$ dari $C$ dengan $C_{1} \cap C_{2}=0$ dan $\varphi: C_{1} \rightarrow C_{2}$ suatu isomorfisma. Karena pemetaan $f+\varphi: A \oplus C 1 \rightarrow B \oplus C 2$ dengan aturan $(f+\varphi)(a+$ $x)=f(a)+\varphi(x)$ adalah isomorfisma, $A \leq A \oplus C_{1}$ dan $B \leq B \oplus C_{2}$, akibatnya $(A, B, f) \leq\left(A \oplus C_{1}, B \oplus C_{2}, f+\varphi\right)$. Kontradiksi dengan kemaksimalan $(A, B, f)$, haruslah $C^{\prime}$ square-free.

Perhatikan bahwa $A \oplus B \oplus C^{\prime}$ ess $M$ sehingga berdasarkan Lema 5, $E(M)=E(A) \oplus E(B) \oplus E\left(C^{\prime}\right)$. Karena $A \cong B$ maka berdasarkan Lema 7 diperoleh $M=(M \cap E(A)) \oplus(M \cap E(B)) \oplus\left(M \cap E\left(C^{\prime}\right)\right)$. Akibatnya $\mathrm{M}=\mathrm{A}$ $\oplus \mathrm{B} \oplus \mathrm{C}^{\prime}$.

Berdasarkan Lema 9, komponen langsung dari $M$ yaitu $A \oplus B$ adalah modul automorfisma invarian. Dari Teorema 10 diperoleh $\mathrm{A}$ dan $\mathrm{B}$ relatif injektif. Submodul $A \oplus B$ dan $C^{\prime}$ juga relatif injektif. Karena $A \cong B$ maka $\oplus \oplus$ B kuasi-injektif. 
Dengan cara sama seperti sebelumnya, bentuk $\Omega=\left\{\left(B^{\prime}, B, t\right) \mid B^{\prime} \leq C^{\prime}\right.$, dan $t: B^{\prime} \rightarrow B$ monomorfisma $\}$ himpunan terurut parsial dengan urutan $\left(B^{\prime \prime}, B, t^{\prime \prime}\right) \leq\left(B^{\prime}, B, t^{\prime}\right)$ jika $B^{\prime \prime} \subseteq B^{\prime}$.

Misalkan $\left(B^{\prime}, B, t\right)$ elemen maksimaldi $\Omega$. Karena $B$ adalah $C^{\prime}$-injektif, $t$ bisa diperluas menjadi monomorfisma $t_{1}$ dari $B^{\prime \prime}$ ke $B$, dengan $B^{\prime \prime}$ essential closure dari $B^{\prime}$. Kemaksimalan $t$ mengakibatkan $B^{\prime}=B^{\prime \prime}$ sehingga diperoleh $B^{\prime}$ closed submodule dari $C^{\prime}$.

Misalkan $D$ essential closure dari $t\left(B^{\prime}\right)$ dan $t^{-1}: t\left(B^{\prime}\right) \rightarrow C^{\prime}$ monomorfisma. Karena $C^{\prime}$ adalah $B$-injektif, $t^{-1}$ dapat diperluas menjadi monomorfisma $\alpha$ dari $D$ ke $C^{\prime}$. Akibatnya $t\left(B^{\prime}\right)=D$. Jadi $t\left(B^{\prime}\right)$ closed submodule dari $B$.

Karena B kuasi-injektifdan $t\left(B^{\prime}\right)$ closed submodule dari $B$ makat $\left(B^{\prime}\right)$ komponen langsung dari $B$. Karena $B$ adalah $C^{\prime}$-injektif maka $t\left(B^{\prime}\right)$ juga $C^{\prime}$ injektif. Akibatnya $B^{\prime}$ adalah submodul $C^{\prime}$-injektif dari $C^{\prime}$. Diperoleh $C^{\prime}=$ $B^{\prime} \oplus C$ untuk suatu $C$.

Akan ditunjukkan $B$ dan $C$ saling ortogonal. Andaikan $B$ dan $C$ tidak saling ortogonal maka $B$ dan $C$ mempunyai submodul tak nol $B_{1}$ dan $C_{1}$ yang isomorfik. Dengan sifat square-free dari $C^{\prime}$ haruslah $B_{1}$ dan $C_{1}$ saling ortogonal. Begitu juga $B_{1}$ dan $t\left(B^{\prime}\right)$ saling ortogonal, sehingga diperoleh $B_{1} \cap t\left(B^{\prime}\right)=0$. Hal ini kontradiksi dengan monomorfisma $t$. Jadi haruslah $B$ dan $C$ saling ortogonal. Diperoleh $C$ dan $A \oplus B \oplus B^{\prime}$ saling ortogonal. Lebih lanjut $A \oplus B \oplus B^{\prime}$ kuasi-injektif. Ambil $X=A \oplus B \oplus$ $B^{\prime}$ dan $Y=C$ diperoleh $M=X \oplus Y$ dengan $X$ kuasi-injektif dan $Y$ squarefree.

\section{SIMPULAN}

Kesimpulan dari penelitian ini adalah modul automorfisma invarian dapat didekomposisi menjadi jumlah langsung modul kuasi-injektif dan modul square-free yang saling ortogonal dan relatif injektif. 
KHAZANAH MULTIDISIPLIN

VOL 1 NO 22020

https://journal.uinsgd.ac.id/index.php/kl

\section{DAFTAR PUSTAKA}

Noyan Er, Surjeet Singh, Ashish K. Srivastava. Rings and modules which are stable under automorphisms of their injective hulls.J. Algebra 379 (2013) 223-229.

T.K. Lee, Y.Zhou. Modules which are invariant under automorphisms of their injective hulls. J. Algebra Appl. 12(2)(2013).

D.S. Passman. 1991. A Course in Ring Theory. AMS. USA.

F.W. Anderson, K.R. Fuller. 1974. Rings and Categories of Modules. Springer-Verlag. New York.

Surjeet Singh, Ashish K. Srivastava. Rings of invariant module type and automorphisminvariant modules.

M. E. Keating. 1998. A firts course in module theory. Imperial College Press. London.

Sri Wahyuni, dkk. 2016. Teori Ring dan Modul. Gadjah Mada University Press. Yogyakarta. 